Daimon. Revista Internacional de Filosofía, n ${ }^{\circ} 85$ (2022), pp. 23-36

ISSN: 1130-0507 (papel) y 1989-4651 (electrónico)

http://dx.doi.org/10.6018/daimon.274421

Licencia Creative Commons Reconocimiento-NoComercial-SinObraDerivada 3.0 España (texto legal). Se pueden copiar, usar, difundir, transmitir y exponer públicamente, siempre que: i) se cite la autoría y la fuente original de su publicación (revista, editorial y URL de la obra); ii) no se usen para fines comerciales; iii) se mencione la existencia y especificaciones de esta licencia de uso. (c) (1) (9)

\title{
Por una nueva política de la verdad: crítica, verdad y parrhesía en Foucault
}

\section{In favour of a new politics of truth: critic, truth and parrhesia in Foucault}

AITOR ALZOLA MOLINA*

\begin{abstract}
Resumen: El presente texto pretende pensar el proyecto que Foucault inició con el análisis de la parrhesía. En él se aborda el problema en relación a otros dos elementos de su obra: la reflexión sobre la función de los intelectuales y sus escritos sobre la noción de crítica. Desde esta perspectiva trataré de mostrar que las investigaciones sobre la parrhesía reflejan el intento de pensar una nueva política de la verdad.
\end{abstract}

Palabras clave: parrhesía, poder, verdad, subjetividad, crítica, intelectual, ethos, ética, Foucault

\begin{abstract}
This text aims to reflect on the project Foucault began with the analysis of parrhesia. This problem is addressed in relation to two other elements of his work: the notion of critique and the function of intellectuals. From this perspective, I will aim to show that the research on parrhesia signifies an attempt to think a new politics of truth.
\end{abstract}

Key words: parrhesia, power, truth, subjectivity, critique, intellectual, ethos, ethics, Foucault

Recibido: 11/11/2016. Aceptado: 14/07/2017.

Quisiera agradecer a las personas que se tomaron la molestia de leer el primer borrador de este trabajo: Pablo López Álvarez, Rodrigo Castro Orellana, Joaquín Fortanet, Jordi Massó y Ana Romeral. Sus sugerencias, comentarios y consejos fueron imprescindibles para su escritura y posterior publicación.

* Investigador pre-doctoral en la Universidad Complutense de Madrid. Realiza una investigación sobre la filosofía de Michel Foucault orientada al estudio del último periodo de su obra bajo la dirección del Prof. Pablo López Alvarez y el Prof. Rodrigo Castro Orellana. Su propuesta de investigación obtuvo el apoyo del Gobierno Vasco a través del Programa de Formación y Perfeccionamiento de Personal Investigador. Ha realizado estancias de investigación en la École Normale Supérieure de Lyon (Francia), en el Centro de Investigaciones Filosóficas de Buenos Aires (Argentina) y en la Universidad a Distancia de Madrid (España). Ha formado parte del comité organizador del Congreso Internacional "La actualidad de Michel Foucault" y coordinado un monográfico para la revista académica Dorsal. Publicaciones recientes: "El silencio de los intelectuales: filosofía, política y parrhesía en Foucault" en Pensamiento. Revista de Investigación e Información Filosófica, vol. 76, 2020, pp. 471-490; "El combate contra las fake news: intelectuales en la era de la posverdad" en Atrolabio: Revista internacional de filosofía, n²3,2019,pp.9-20.Correo: aitor.alzola@ucm.es 


\section{Introducción}

Los obstáculos presentes a la hora de abordar el tema de la parrhesía en la obra de Foucault ya han sido señalados. Como dicen Ángel Gabilondo y Fernando Fuentes Megías (2004), resulta difícil para los lectores del pensador francés abordar los textos en los que retorna a la Antigüedad grecolatina. Antes resultaba sencillo ver en sus trabajos un ejemplo de intelectual comprometido que desarmaba el discurso del poder, y el vínculo de los escritos con la más rabiosa actualidad era explícito para muchos. Pero con la incursión en la filosofía y cultura de la Antigüedad clásica, los temas familiares sobre el poder o el saber son relegados por la enigmática reflexión en torno al decir veraz de la parrhesía.

La profesora Judith Revel (2014) identifica dos grandes maneras de leer la obra del pensador francés en la actualidad: una primera que abogaría por encontrar una temática principal que se desarrolla y progresa a lo largo del tiempo; y otra que vería tres grandes temas independientes entre ellos, sancionados por grandes rupturas y saltos en su pensamiento. Con la primera nos encontraríamos con aquellas lecturas que vienen a acentuar la unidad temática: existiría una identidad esencial por debajo de las diferencias - ya sea el poder, el saber o, como es habitual ver últimamente, el sujeto (Castro, 2005; Lanceros, 1997)- , que otorgaría una coherencia y linealidad lógica a su obra. Con la segunda, por otro lado, se estaría diciendo que Foucault siempre está formulando cosas radicalmente diferentes, que de una etapa a otra propone un cambio tan radical que los nuevos postulados no harían posible asimilarlo desde los parámetros que había mantenido con anterioridad (Deleuze, 2003; Dreyfus \& Rabinow, 2001). ${ }^{1}$

Sin duda, las diferentes lecturas de la obra de Foucault están íntimamente relacionadas con el acceso a nuevos materiales que hacen necesario reformular y modular la visión que se tiene del mismo. Conviene recordar que, hasta la reciente publicación de los últimos cursos del Collège de France, los materiales sobre la parrhesía eran escasos. Pero a pesar de estas publicaciones, las lecturas antes mencionadas han condicionado, hasta cierto punto, la aproximación al problema de la parrhesía en el ámbito hispanohablante. El decir veraz es abordado como una prolongación del tema más general del sujeto (Alvarez Yagüez, 2013), o bien como un ejemplo más de la ruptura que se consuma en el filósofo francés con la vuelta a los griegos (Moreno Pestaña, 2011).

Como declara Foucault en una conferencia en 1983, la investigación sobre la parrhesía tiene que enmarcarse en un estudio más general sobre el discurso crítico. El filósofo francés afirma que dicho trabajo forma parte de "una genealogía de la actividad crítica en la filosofía occidental" (Foucault, 2004a, p. 213). No cabe duda de que la deriva hacia la Antigüedad clásica responde en primera instancia a la necesidad de realizar una genealogía del sujeto de deseo (Foucault, 2003). Viaje en el que se desarrolla el análisis de las formas de subjetivación y el cuidado de sí. Sin embargo, si atendemos a las palabras pronunciadas en esa conferencia en EEUU, el giro al problema de la parrhesía parece sacarnos momentáneamente del tema general del sujeto para situarnos frente a otro problema: el de la crítica. ${ }^{2}$

1 Para un análisis más detallado de las lecturas que se sitúan en esa esfera véase el trabajo de Lanceros (1997), Alvarez Yagüez (2013) y Revel (2014)

2 Una reciente publicación italiano-francesa ha dedicado precisamente un monográfico a explorar la relación entre crítica y parrhesía en Foucault (Cremonesi, Irrera, Lorenzini, \& Tazzioli, 2014). 
Ese desplazamiento hace necesario retomar una conferencia que pronunció en 1978 que llevaba precisamente por título «¿Qué es la crítica?»(Foucault, 1995). Esta intervención tiene como objeto preguntarse sobre el origen y significado de la crítica, situando el foco de atención en las relaciones entre el poder, el sujeto y la verdad. Se inaugura en este momento toda una serie de reflexiones que se prolongarán en el tiempo. Forma parte de este conjunto la conferencia pronunciada en 1983, y que lleva por título «¿Qué es la Ilustración?» (Foucault, 1993b). Por último, tenemos un texto que en español se ha traducido como "Seminario sobre el texto de Kant «Was ist Aufklärung?»" (Foucault, 2006). Este no es sino la transcripción publicada en 1984 de la clase que inauguró el curso de 1983 en el Collège de France. Precisamente, el primer curso que Foucault dedica de manera exclusiva al tema de la parrhesía. Encontramos así que la reflexión sobre la crítica se impone como prolegómeno obligatorio y punto de arranque para introducirnos en las investigaciones sobre el problema del decir veraz en la Antigüedad clásica.

Si bien es cierto que comenzamos a encontrar líneas de trabajo que tratan de explorar justamente el vínculo entre crítica y parrhesía (Mascaretti, 2014; Rambeau, 2012), estas centran su labor en equiparar la crítica con otra noción de aparición tardía en la obra del filósofo francés: la problematización. Se trata de un acercamiento que puede resultar provechoso para clarificar el significado de la crítica. Sin embargo, no arroja luz respecto al abandono parcial de las investigaciones sobre el cuidado de sí y el repentino interés en buscar el origen y las diferentes expresiones de la parrhesía. Del mismo modo, estos trabajos dejan de lado el conjunto de textos que Foucault dedicó al problema del intelectual. Trabajos que, como ya han señalado algunas investigaciones (Adorno, 2010; Castro, 2005; Gros, 2010a), contienen claras resonancias con el tema de la parrhesía que hace ineludible tomarlos en consideración. Siguiendo este hilo, tal y como trataré de demostrar más adelante, se pone de manifiesto que el centro del problema de la crítica lo constituye la verdad (Adorno, 2010). Lo que, a nuestro entender, permite ensayar una aproximación más productiva a la parrhesía, vinculada ella también con la verdad (Gros, 2010b).

No es la intención de este texto hacer una reconstrucción de la genealogía de la crítica de la que Foucault habla (Folkers, 2016). Pretendemos, por el contrario, atender a las diferentes líneas que se entrecruzan en el origen de ese proyecto y las modificaciones que acabaron produciendo en la noción misma de crítica. Para ello, empezaremos por aclarar el concepto de crítica en Foucault a partir de los textos señalados más arriba. Creemos que en esos trabajos el rasgo principal de la crítica es producir efectos de desujecion en los individuos. A continuación, mostraremos cómo la reflexión sobre la crítica se remonta hasta la época en la que Foucault establece un diálogo con el marxismo. Un debate que tiene como escenario principal la figura del intelectual y la necesidad de superar los límites propios a ese modelo. De esta manera, se verá el vínculo estrecho entre discurso crítico y verdad, y la necesidad de elaborar una nueva política de la verdad que sustente la crítica. Finalmente, trataremos de realizar una aproximación a la noción de parrhesía, donde se esboza una nueva política de la verdad que, al mismo tiempo, reformula la noción misma de crítica que Foucault había venido utilizando. Una crítica que deja de tener por función meramente la desujeción para adoptar una función etopoyética. 
Si la parrhesía debe ser enmarcada dentro de una genealogía de la crítica, resulta necesario aclarar el significado que Foucault otorga a la palabra "crítica". La lectura de los textos señalados con anterioridad (Foucault, 1993b, 1995, 2006) muestran un alejamiento claro respecto a lo que se entiende generalmente por dicha actividad. No se trata aquí de entenderla como un mero acto a través del cual se trata de poner una objeción a esta u otra afirmación. Tampoco encontraremos una práctica que se asocia a la búsqueda paciente y minuciosa del error, la incongruencia, la falta de lógica o ausencia de razón de una afirmación particular. Para Foucault, la crítica no tiene como objetivo encontrar los agujeros y fallas de un discurso presentado como unitario y perfecto. Por lo tanto, no hay que entenderla como una mera expresión de desacuerdo, tal y como comúnmente se la entiende.

El filósofo francés entiende la noción de crítica en un sentido más radical. La crítica es la expresión material del rechazo ante una forma de gobierno. La imagen que evoca en este sentido es significativa: las luchas religiosas y espirituales de la segunda mitad de la Edad $\mathrm{Media}^{3}$. Luchas que hay que entender como ejemplos de rebeldía, insubordinación, contraconducta, resistencia. La crítica es una de las formas que podría adquirir la revuelta. La noción se aleja así de la idea blanda de oposición o desencuentro con ciertas instituciones de gobierno para situarlo en un sentido más amplio de lo político. La crítica se ejerce siempre contra el poder, contra toda forma de poder que atraviesa la sociedad: desde las estructuras institucionales más reconocibles hasta los pequeños gestos cotidianos cuya existencia nosdesvela la consolidación de cierta forma de dominación. La crítica, entendida así, es ante todo una toma de posición en la que, necesariamente, se tendrá de frente al poder. Ahora bien, ¿cómo hay que entender este posicionamiento frente al poder, esta crítica del poder?

Foucault pone tres ejemplos históricos (Foucault, 1995). La primera alude a la lucha en torno a las sagradas escrituras a principios de la modernidad. Encuentra en la Reforma protestante el momento más álgido de una serie de movimientos espirituales que se levantan contra la autoridad de la Iglesia. Estos movimientos se rebelan contra una forma determinada de relacionarse con la palabra sagrada de Dios. Colocan en el centro de su actividad un cuestionamiento de la verdad de la Iglesia y de la veracidad de sus interpretaciones. La segunda manifestación histórica señalada por Foucault se sitúa también en los orígenes de la Edad Moderna. Se trata de la lucha en defensa del derecho natural y que pone en jaque la autoridad del soberano y su poder absoluto. El poder del monarca, asumido como algo natural y como una verdad incontestable, encuentra un límite y una fuerte impugnación en la reivindicación de los derechos del hombre. De esta manera, cierta verdad que se sustenta sobre la tradición se debilita y erosiona perdiendo todo poder de coacción. En tercer lugar, Foucault asocia la crítica con el largo proceso de la aparición de la ciencia. Entiendo por

3 "lo que quería subrayar [...] es que me parece que la historia de la actitud crítica, en lo que tiene de especifico en Occidente [...] tiene que buscar su origen en las luchas religiosas y las actitudes espirituales de la segunda mitad de la Edad Media. En el momento justamente en que se plantea el problema: ¿cómo ser gobernado, es que vamos a aceptar ser gobernados así? Es entonces cuando las cosas están a su nivel más concreto, más históricamente determinado: todas las luchas alrededor de la pastoral en la segunda mitad de la Edad Media han preparado la Reforma, y yo creo que han sido la especie de umbral histórico sobre el cual se ha desarrollado esta actitud crítica" (Foucault, 1995, p. 17). 
esto una transformación histórica lenta en la que la autoridad, en tanto que fuente y origen de verdad, se pone en cuestión. Poco a poco se reemplaza por la necesidad de establecer mecanismos reglados con capacidad de verificación y, por tanto, de procesos de producción de verdad gobernados por métodos objetivos.

Los ejemplos mencionados arriba ponen como objeto principal de la crítica la verdad. La crítica tiene como tarea fundamental una puesta en cuestión radical de la verdad, sea esta una verdad de la Iglesia o la verdad que imponen las leyes y la tradición, o la verdad que emana de la autoridad - del maestro, el padre de familia, etc. - . Pero encontramos otro elemento común en todos ellos: se trata siempre de formas de sometimiento, de formas de obediencia, que son impuestas a través de la fuerza de la verdad o, mejor dicho, de la necesidad de la verdad, del imperativo que ella implica siempre de manera implícita. Se trata pues de una crítica del poder que gobierna a través de la verdad. Porque el poder al que se refiere aquí Foucault no hace obedecer - únicamente - a través de la violencia física o la coerción. El poder conduce a los individuos a través de una verdad que los sujetos asumen como propia. Son los sujetos mismos quienes obedecen al interiorizar esa verdad. Y solamente rompiendo la relación que tiene con ella aparece la posibilidad de desobedecer, de oponerse al poder. La verdad es un elemento fundamental de la crítica porque a través de ella se aúnan poder y sujeto, el imperativo y la necesidad de obediencia. ${ }^{4}$

Por lo tanto, la crítica en la que piensa Foucault debe analizar las relaciones entre poder, verdad y sujeto. Para ello debe "ocuparse de los discursos que articulan lo que pensamos, decimos y hacemos, como otros tantos acontecimientos históricos" (Foucault, 1993b, pp. 15-16). La aproximación histórica de los discursos permite cuestionar su verdad, entendida como indiscutible necesidad. Nos libera de los efectos de poder y obediencia que induce en los individuos y los constituye como sujetos. Por consiguiente, si el poder produce verdad y sujetos atados a través de esa verdad, la tarea de la crítica debe ser revertir ese proceso. El discurso crítico adopta las veces de una herramienta de combate contra el poder que busca deshacer el camino trazado en la producción de subjetividades sometidas. Frente a los procesos de subjetivación puestos en marcha a través de los dispositivos de poder que producen docilidad, la crítica es un discurso que abre las vías para un proceso de desubjetivación ${ }^{5}$ liberador. De esta manera, podríamos concluir diciendo que la crítica es "el movimiento por el cual el sujeto se atribuye el derecho de interrogar a la verdad acerca de sus efectos de poder, y al poder acerca de sus efectos de verdad" (Foucault, 1995, p. 8) y que tendría "por función la desujeción en el juego de lo que se podría denominar, con una palabra, la política de la verdad” (Foucault, 1995, p. 8).

\section{II}

El concepto de ideología tiene una larga tradición en el pensamiento marxista. Funciona como eje en torno al cual se elabora el discurso crítico marxista y se define la labor del intelectual. Si bien es verdad que no es fácil delimitar un uso unívoco del concepto dentro de

4 "Hay dos significados de la palabra sujeto: sometido a otro a través del control y la dependencia, y sujeto atado a su propia identidad por la conciencia o el conocimiento de sí mismo. Ambos significados sugieren una forma de poder que subyuga y somete" (Foucault, 1988, p. 7).

5 Miguel Morey (1999), por ejemplo, sitúa en ese gesto uno de los elementos más característicos de la filosofía de Foucault. 
la larga tradición del marxismo, al menos podemos distinguir dos usos comunes del mismo (Eagleton, 1997). El primero podría calificarse de político. Entiende la ideología como todo discurso que tiene por objeto defender ciertas ideas asociadas a una u otra corriente política y los valores y creencias que encarna en relación a la organización social. Cuando se dice que el liberalismo o el comunismo son ideologías, estaríamos haciendo uso de esa acepción del concepto.

Pero también habría otro uso que podríamos denominar epistemológico. Este se asocia a la mistificación y la distorsión, a saber, con la falsificación de la realidad contenida en un discurso dado. Con ello se trata de señalar la incapacidad de los individuos para aprehender los mecanismos profundos que hacen funcionar la sociedad capitalista. El individuo recoge así una realidad distorsionada y, en consecuencia, es portador de una "falsa conciencia". De ahí la necesidad de "un discurso especial conocido como ciencia para adentrarse en sus formas fenoménicas y mostrar su esencia" (Eagleton, 1997, p. 125). Dicha ciencia no es otra cosa que el materialismo histórico que practica la teoría marxista de la época.

El rechazo al término de ideología ${ }^{6}$ en Foucault puede rastrearse al menos hasta la publicación de El nacimiento de la clínica. Pero no es hasta entrada la década de los setenta cuando empieza a dedicar cada vez más palabras y reflexiones, sueltas pero constantes, al problema $^{7}$. Esta deriva culmina finalmente con la tentativa de teorizar sobre la figura del intelectual. En este punto se cruzan las reflexiones sobre las insuficiencias de la ideología como herramienta analítica y la necesidad de pensar de otra forma la encarnación del discurso crítico. La figura del intelectual es descrita con mayor profusión en una entrevista realizada en 1976 (Foucault, 2000b), pero encuentra una primera tentativa de esbozar sus contornos en una entrevista realizada a Gilles Deleuze en 1972 (Foucault \& Deleuze, 2000). También retomará el tema con motivo de una conferencia pronunciada en Tokio a finales de los setenta (Foucault, 1999).

Estos textos nos muestran al intelectual como una figura recurrente en la historia de Occidente. Ya sea a través de la figura más antigua del filósofo, o de la más moderna del escritor comprometido, puede rastrearse la presencia de esas personas que tienen por función principal "poner límites al exceso de poder" (Foucault, 1999, p. 113), o hacer las veces de un "contrapoder" (Foucault, 1999, p. 117) en las sociedades. Un papel que puede ser asimismo desdoblado y adquirir formas diferentes. El intelectual puede aparecer bajo la forma del legislador, bajo la forma de un pedagogo, o, incluso, adoptando las formas cínicas para exhibir su disconformidad.

Esta figura del intelectual adquiere unos matices particulares en la primera mitad del siglo XX. Foucault utiliza el término de "intelectual universal" para distinguirlo (Foucault, 2000 b, pp. 49-55). Ese intelectual originario, que habla en nombre de la justicia y de la verdad, es reformulado y repensado a partir de las categorías del marxismo. Por consiguiente, el intelectual universal designa al individuo que, en virtud de su conocimiento de la ciencia marxista, tiene la capacidad de enunciar una verdad que es continuamente falseada por la

6 La relación de Foucault con el pensamiento marxista no se limita al problema de la ideología. Y aunque no tenemos espacio para tratarlo en este artículo, se ha tenido presente el trabajo realizado por Poster (1987) y Eribon (1995, 2004) en esa dirección.

7 El rechazo al término de ideología puede encontrarse así en La arqueología del saber (Foucault, 2004b) o La verdad y las formas jurídicas (Foucault, 2000a), por mencionar solo alguna de las referencias más sonadas. 
ideología. La capacidad de discernir la esencia de los fenómenos le permite ver la verdad oculta por la confusión del mundo moderno capitalista y señalar el camino para la liberación. La clase obrera, que por su condición está llamada a transitar ese camino, es incapaz de cumplir la misión histórica que tiene por delante, precisamente, por el influjo de la ideología. En consecuencia, el intelectual debe tomar la palabra para luchar contra las opiniones erróneas y la ofuscación del pensamiento. El intelectual universal, cuenta Foucault, "decía la verdad a quienes aún no la veían, y en nombre de aquellos que no podían decirla: encarnaba a la vez la conciencia y la elocuencia" (Foucault \& Deleuze, 2000, p. 107).

A este intelectual universal Foucault opone la figura del "intelectual específico" (Foucault, 2000b, pp. 49-55). Aunque la caracterización de esta tipología de intelectual resulta a veces oscura, podemos señalar una nota distintiva: no pretende representar lo universal. ${ }^{8}$ Hay que entender esto como el rechazo a dictar una verdad universal. Pero igualmente, y en primer lugar, como el rechazo a concebir la verdad como un dato natural. En lugar de entenderla como un objeto del mundo, instalada de antemano y a la espera de que la ciencia ponga luz sobre ella, la considera como el producto de "un conjunto de procedimientos reglados por la producción, la ley, la repartición, la puesta en circulación, y el funcionamiento de los enunciados" (Foucault, 2000b, p. 55). Por lo tanto, no hay ni verdad que descubrir entre la maraña de fenómenos que la ocultarían en un primer acercamiento ni búsqueda de la esencia de las cosas.

Lo que marca la diferencia entre la figura del intelectual específico y el intelectual universal es la concepción de la verdad. Si bien es cierto que el intelectual universal critica la verdad que emana del poder, lo hace en tanto que se cree en posesión de una verdad más pura. Pero nunca la pone en duda. No se pregunta por su valor ni por su origen. Es decir, no hace genealogía alguna. Admite que tan sólo existe la posibilidad de una Verdad cuya posesión daría el derecho a la crítica, y cuyo conocimiento solo es posible a través de la ciencia. En este caso, la disciplina científica del marxismo. A partir de ahí, el intelectual universal enarbola la bandera de la Verdad y proclama una lucha a su favor. Por el contrario, para Foucault no se trata de encabezar un "combate «en favor de la verdad», sino en torno al estatuto de verdad y el papel económico-político que éste juega" (Foucault, 2000b, p. 54). Hay que situar la tarea del intelectual específico en el plano de una política de la verdad, lejos del campo del conocimiento en el que la sitúa el intelectual universal. ${ }^{9}$

La idea de concebir la verdad como un producto histórico y un efecto del discurso hace que la tarea del intelectual específico se confunda y se mezcle con la labor del historiador, ya que "justo gracias a la historia se puede problematizar y sustraer aun fundamento ficticio lo que se percibe como una necesidad racional" (Adorno, 2010, p. 37). Foucault tratará de definir precisamente esa idea de crítica a finales de los años setenta, como ya hemos podido ver, atendiendo a su doble vertiente genealógica y arqueológica. Pero más allá de esa doble tarea encontramos en esta reflexión sobre el intelectual un elemento novedoso. No se trata solo de analizar la política de la verdad con vistas a producir efectos de desujeción. Foucault también sugiere la necesidad de elaborar una "nueva política de verdad":

8 Para un análisis más detallado y comparativo de la figura del intelectual específico véase el trabajo de Fortanet (2010).

9 Esta distinción en Foucault entre una verdad de corte epistemológico y de corte nietzscheano, ha sido señalado también por Lorenzini (2010). 
El problema político esencial para el intelectual no es criticar los contenidos ideológicos que estarían ligados a la ciencia, o hacer de tal suerte que su práctica científica vaya acompañada de una ideología justa. El problema político del intelectual es saber si es posible constituir una nueva política de la verdad (Foucault, 2000b, p. 55).

No se encuentra descripción alguna de esa nueva política de la verdad en los textos que hemos analizado sobre el intelectual. Tampoco la encontramos en los textos de finales de los setenta y principios de los ochenta, donde Foucault se sumerge en esa reflexión sobre la crítica. Se constata así una tensión no resuelta del discurso crítico y de la función del intelectual que parece abrirse en esta época, pero que sin embargo no llega a cerrarse. No llega a tener una tentativa de respuesta hasta encontrarse con el problema de la parrhesía como forma del decir veraz en la Antigüedad grecolatina.

\section{III}

Al analizar el concepto de parrhesía, Foucault resalta el carácter escurridizo de su significado. Trata de rastrear el variado uso de la palabra en los diferentes momentos históricos y en los diversos contextos, mostrando las modulaciones que sufre en cada momento. De este modo, lejos de ofrecer un contenido unívoco y cerrado, trata de dibujar una constelación de los elementos que, interrelacionados, dotan de sentido a la palabra. Pero sin perder de vista que dichos elementos tendrán que ser parte constitutiva de la misma para que su significado no se desvirtúe. Así, Foucault nos propone un acercamiento genérico a la parrhesía entendida como:

[...] una forma de actividad verbal en la que el hablante tiene una relación específica con la verdad a través de la franqueza, una cierta relación con su propia vida a través del peligro, un cierto tipo de relación consigo mismo o con otros a través de la crítica (autocrítica o crítica a otras personas), y una relación específica con la ley moral a través de la libertad y el deber (Foucault, 2004a, p. 46).

Foucault no tiene dudas sobre el lugar que la crítica ocupa como ingrediente fundamental de la idea de parrhesía. El uso originario de la palabra en el campo de la política atestigua este hecho. A través del análisis de las tragedias de Eurípides la parrhesía aparece vinculada al imaginario político griego de la época. Por un lado, está vinculada al derecho a tomar la palabra reservado a aquellos que son considerados ciudadanos y que, por lo tanto, pueden participar de los asuntos públicos. Pero, por otro lado, designa al individuo que alza la voz ante la palabra de quién, al ocupar un espacio de poder, enuncia una verdad que es considerada errónea, falsa, una mentira. ${ }^{10}$

En este sentido, la noción de parrhesía no parece muy alejada de la concepción del discurso crítico del intelectual que hemos mencionado con anterioridad. Sin embargo, las connotaciones

10 "But someone who does not have parresia is at the same time subject to the master's foolishness, to his madness; that is to say, you see the idea appearing that parresia is not only a right, in its foundation and origin, if you like, but also that its function is to speak something like reason and truth to those who are wrong, who do not possess the truth [...] Parresia speaks truthfully; it is therefore the right to speak the truth in front of someone who is mad, someone who does not possess the truth" (Foucault, 2015, p. 225). 
de la palabra son lo suficientemente variadas como para negarnos a dejarlo reposar únicamente sobre este pilar. Si bien es cierto que se la entiende como discurso crítico, su significado no se agota ahí. La persona que hace uso de la parrhesía no se limita a desdibujar la verdad que viene de arriba para vaciarlo de poder. La parrhesía también tiene un elemento positivo, productivo.

Foucault analiza los diferentes usos de la palabra parrhesía, pero se decanta por profundizar en la acepción que toma forma bajo el cuidado de sí. El porqué de esta elección parece claro: se encuentra con el problema de la parrhesía en el curso sobre La hermenéutica del sujeto (Foucault, 2005), cuando está, precisamente, analizando las relaciones entre verdad y sujeto. Es decir, en pleno proceso de búsqueda de elementos emancipadores en los procesos de subjetivación. El cuidado de sí provee de un espacio de reflexión en el que, lejos de buscar técnicas de dominación, se elaboran, se reflexionan y enumeran técnicas que buscan liberar al individuo de cualquier relación de dependencia. Entre las técnicas y procedimientos que permiten construir sujetos más autónomos aparece con insistencia el papel del maestro de conciencia.

Este hecho llama la atención porque el maestro está obligado a decir una verdad (Foucault, 1993a), mientras que en el dispositivo encontrado en el cristianismo, la obligación de decir la verdad recae sobre el alumno. Dentro de la cultura de sí, la verdad del maestro debe servir al proceso de liberación y de autonomía de los sujetos. Sucede así que la verdad pasa de ser un elemento para el gobierno de las conductas a ser una pieza imprescindible para su liberación, para elaborar dispositivos de resistencia. Y esa verdad que enuncia el maestro será caracterizado de una forma concreta: parrhesía.

Esto nos sitúa ante una de las características más importantes de la parrhesía, remarcada por Foucault en varias ocasiones. Me refiero al carácter etopoyético ${ }^{11}$ de este decir veraz singular. La parrhesía no es solamente un discurso de carácter crítico. No se reduce a destruir una verdad que viene de arriba y atraviesa a los sujetos, sino que ella misma tiene que producir o decir una verdad que sirva como sustento en esos procesos en los que se aúnan sujeto y verdad.

La parrhesía tiene que alentar el alma de su oyente. Tiene que estimularlo a conducirse de esta u otra manera. Tiene que ser un incitador que moldee la conducta del sujeto. La parrhesía, en tanto que tiene una función etopoyética, debe influir, necesariamente, en la conducta de los hombres.

De ahí la constante tensión entre la parrhesía y la retórica. La parrhesía se sitúa en un espacio colindante y limítrofe respecto de la retórica. Sin embargo, se diferencia de ella. Esta distinción incumbe al contenido de lo que dice el parresiastés y al individuo que hace uso de la retórica. El artista de la retórica no se vincula con aquello que dice para convencer a su interlocutor. Puede manifestar un juicio sobre un asunto reservándose una opinión bien distinta en su interior. Entre lo que dice y piensa no tiene por qué existir ningún tipo de identidad, ya que el fin último es mover las pasiones de sus oyentes para persuadirlos e influir en su opinión. Por el contrario, si el parresiastés dice una cosa, es necesario que lo que dice sea exactamente lo mismo que piensa. Tiene que haber un vínculo entre lo que dice y piensa. No puede haber

11 "Digamos por tanto, en forma muy esquemática, que el parresiasta no es el profesta que dice la verdad al desvelar, en nombre de otro y enigmáticamente, el destino. El parresiasta no es un sabio, que en nombre de la sabiduría, dice, cuando quiere y contra el telón de fondo de su propio silencio, el ser y la naturaleza (la physis). El parresiasta no es el profesor, el docente, el hombre del saboir-faire que dice, en nombre de una tradición, la tekhne. [...] el parresiasta pone en juego el discurso veraz de lo que los griegos llamaban el ethos" (Foucault, 2010, p. 41). 
contradicción entre una y otra. La coincidencia entre lo que dice y piensa tiene que ser absoluta. En el parresiastés existe un vínculo orgánico entre la palabra y el pensamiento. Sin la existencia de ese vínculo, que es un vínculo que condiciona, no se puede hablar de parrhesía.

Por eso la parrhesía es entendida también como una palabra franca, una palabra transparente, pues se hace manifiesto en ella aquello que el orador piensa. La transparencia entre lo que se dice y se piensa es tal que Foucault llega a calificarlo como "el grado cero de esas figuras retóricas que intensifican las emociones del auditorio" (Foucault, 2004a, p. 48). En ella, sin ninguna necesidad de añadir algo a lo que se dice, se consigue alcanzar el mismo efecto en los oyentes.

Pero si bien la parrhesía tiene similitudes con la retórica, esta no puede ser analizada como una figura retórica más. Debe ser examinada como una modalidad del decir veraz o lo que desde el curso Del gobierno de los vivos Foucault (2012) viene teorizando como aleturgia..$^{12}$ Esto quiere decir que la verdad se estudia no tanto atendiendo al grado de parentesco que pueda encontrar cierta enunciación con la realidad hacia la que apunta, sino de las condiciones que tendrá que cumplir el sujeto para que aquello que dice sea considerado como verdadero. Dicho con otras palabras, se trata de abandonar los análisis epistemológicos de la verdad para introducir en su lugar formas de valorar y verificar dicha verdad sustentadas por el sujeto que las enuncia.

Conviene tener presente esta forma de aproximación al concepto de verdad que opera en el parresiastés para no extraviarse en el análisis que realiza Foucault, profuso y detallado. A través de los diferentes textos de Eurípides, de Platón y de los cínicos o los estoicos, se perfila una pregunta que ronda continuamente el texto y que le otorga a este conjunto heteróclito su corpus: ¿De qué tipo de verdad se trata en la práctica parresiástica? ¿Cuál es la modalidad de la verdad contenida en ella? Dicho de otra manera, si el parresiastés dice la verdad, ¿de dónde adquiere esa verdad su valor, su autoridad, su fuerza? ¿Cuáles son las condiciones que el sujeto tendrá necesariamente que cumplir para que lo que diga sea considerado como verdadero? Estas preguntas rigen el análisis del decir veraz de la parrhesía, lo que constituye, en palabras del filósofo francés, una “ontología del discurso verdadero" (Foucault, 2009, pp. 315-316).

En este sentido, resulta pertinente preguntarse por la política de la verdad que opera en la parrhesía. Sin duda, encontraremos ahí una política con unas características particulares. Si se afirma que el parresiatés dice la verdad, es porque existe una equivalencia entre lo que dice y lo que hace. El mismo es el testigo, el testimonio y, al mismo tiempo, la prueba fehaciente de la verdad de sus palabras. Encontramos una armonía entre palabra y vida específica del decir veraz del parresiastés. Se podría decir que lo que hace el parresiastés no es sino poner en palabras, y de manera racional, su propia vivencia, su experiencia y su vida. ${ }^{13}$

Es precisamente esa armonía entre palabra y vida, entre lo que dice y hace, lo que convierte a Sócrates en un parresiastés. Foucault rescata el Laques de Platón como ejemplo. En este diálogo platónico que versa sobre "el valor" encontramos dos interlocutores tratando

12 "[Con la aleturgía ] Se trataría de analizar, no en modo alguno, cuáles son las formas del discurso que permiten reconocerlo como veraz, sino: bajo qué forma, en su acto de decir la verdad, el individuo se autoconstituye y es constituido por los otros como sujeto que emite un discurso de verdad" (Foucault, 2010, p. 19)

13 "El director de la existencia antigua se caracteriza en efecto por tomar la palabra directa, francamente, y para autentificar la verdad de lo que defiende avala con su propia conducta: la verdad de lo que presento resplandece en mis actos" (Gros, 2010a, p. 132) 
de determinar cuál sería el mejor maestro para sus hijos. Piensan, para tal cometido, en la figura de Estesilao. Este es descrito de la siguiente manera por Foucault:

[...] atleta, técnico, actor y artista, lo cual significa que aunque es muy habilidoso manejando las armas, no utiliza su habilidad para combatir realmente al enemigo, sino sólo para hacer dinero ofreciendo demostraciones públicas y enseñando a los jóvenes (Foucault, 2004a, p. 129).

Estesilao puede combatir de manera bella, pero él mismo nunca ha combatido en una guerra, así que no es considerado un soldado real. Sin embargo, Sócrates, que sí participó como soldado en Delio, atesora la experiencia que le permite hablar con propiedad. Sus palabras y sus actos concuerdan en este sentido. Foucault es claro al respecto: "Este acuerdo armónico es lo que distingue a Sócrates de un sofista: el sofista puede pronunciar bellos y sutiles discursos sobre el valor, pero él mismo no es valiente" (Foucault, 2004a, p. 136).

Si las palabras de Sócrates pueden ser consideradas verdaderas, no es porque lo que diga concuerde con la realidad. No se trata de que el discurso sea un reflejo del mundo que nos rodea y haya sido capaz de captar la ley fundamental que, bajo la oscuridad de los fenómenos, nos muestra la esencia de las cosas eternas. La verdad del parresiastés no adquiere ahí su garantía de veracidad. Lo que da fuerza y autoridad a sus palabras, lo que otorga validez y autenticidad a su discurso es, por el contrario, el hecho de que el discurso del hablante es puesto a prueba por su propia vida. Y que, como resultado de esta puesta a prueba de la palabra por la vida, se encuentre una armonía, una sintonía. La constitución de la verdad es el resultado de una correlación necesaria entre vida y pensamiento del sujeto que habla. En última instancia, son los actos del sujeto que habla los que harán la prueba de la verdad de sus palabras.

\section{Conclusiones}

La parrhesía adquiere como discurso crítico particularidades que conviene remarcar. No aparece solamente como una forma de interpelar una verdad que, lanzada desde una esfera de poder, es considerada errónea. La parrhesía es un discurso que cuestiona la verdad heredada. Pero, al mismo tiempo, pronuncia una verdad que tiene que apelar a un sujeto en constitución, y que tiene como último fin, un sujeto emancipado. Además, ese decir veraz de la parrhesía encuentra su fundamento de verdad en la relación que existe entre la propia vida del hablante y su discurso. Encontramos así dos elementos que marcan el carácter de la parrhesía como discurso crítico: su vocación etopoyética y la fundamentación ética de la verdad que enuncia.

Se puede constatar así un ligero desplazamiento respecto a lo que Foucault entiende por crítica. Un desplazamiento de tipo cronológico, en primer lugar. Si en los textos de los años setenta se sitúa el origen de la actitud crítica en las luchas religiosas y espirituales de finales de la Edad Media, el análisis de la parrhesía hará retroceder la aparición de ese gesto comprometido y valeroso a los textos de Eurípides en la antigua Grecia. Por otro lado -y aquí tenemos un segundo desplazamiento-, en los textos de finales de los setenta Foucault aboga por una crítica que centre su tarea en la desujeción. De esta manera, se concibe la crítica como una tarea que aboga por el desmantelamiento de cualquier verdad heredada. La crítica es entendida así en términos puramente negativos. Ella no tiene otro fin que derrum- 
bar los cimientos sobre los cuales se construyen nuestras certidumbres. Ahora bien, con el análisis de la parrhesía vemos como la función de la crítica es entendida en un sentido más amplio. Ya no se trata solamente de cuestionar determinada verdad. La parrhesía pronuncia una verdad otra. Así, la crítica deja de tener una función meramente negativa para adoptar una función positiva, constructiva.

Esta verdad otra, sin embargo, opera bajo unas coordenadas diferentes respecto a la verdad a la que apela el intelectual universal en su crítica. La política de la verdad en una y otra no son equivalentes. Hay toda una morfología de la verdad que muestra diferencias sustanciales. Mientras que en el intelectual universal prima, como condición muda sobre la cual pivota dicho discurso, la presencia de una forma de verdad epistemológica, la parrhesía pone en acción una forma de verdad ética. La primera adquiere su valor en relación al conocimiento, mientras que la segunda solamente es sustentada por la propia vida.

Dos formas de verdad que resultan en dos formas diferentes de entender el discurso crítico y el papel del intelectual. Pero cuya formulación y desarrollo no puede ser entendida sin las referencias cruzadas que encontramos entre ellas. Es precisamente la constatación de los límites del discurso crítico marxista lo que alumbra el análisis de la parrhesía, y lo que puede ayudarnos a entender lo que hay en juego en ellas. En este sentido, pensamos como Adorno (2010) que la parrhesía responde a la necesidad de repensar los cimientos sobre los cuales será posible pronunciar un discurso crítico, entendido ahora, como una forma específica del decir veraz.

La investigación sobre la parrhesía reactualiza y retoma una discusión que se había iniciado con una interrogación sobre de la función del intelectual. Ese cuestionamiento tiene lugar en el marco de un diálogo siempre tenso con la tradición del pensamiento político más importante de aquella época: el marxismo. En este sentido, más que un abandono de ciertas posiciones políticas (Moreno Pestaña, 2011), pensamos como Poster (1987) que es necesario ver en los diferentes gestos de Foucault el intento de superar los límites inherentes a posiciones políticas concreta. Más que un abandono de posiciones políticas críticas o un repliegue sobre posiciones individualistas, a nuestro entender, ponen de manifiesto un intento de repensar las bases sobre las que construir, precisamente, esas posiciones críticas.

Visto de esta manera, los trabajos sobre la parrhesía no pueden ser considerados como un elemento continuista dentro del itinerario del filósofo francés, y mucho menos como un apéndice de las investigaciones en torno al sujeto (Alvarez Yagüez, 2013). Más bien, encontramos en ellos una reactualización de una problemática que aparece de manera intermitente, pero constante, en sus anteriores reflexiones. Parece claro que la parrhesía requiere de una aproximación diferenciada respecto al problema de la estética de la existencia. Ya no se trata tanto de indagar en unas técnicas de sí particulares para explicar los procesos de subjetivación, sino de atender a una morfología específica de la verdad que remite, sin duda, a esa historia de la verdad de la que habla Foucault en sus últimos años (Terrel, 2012).

Ni ruptura total ni continuidad sin asperezas. Como ha señalado Gros (2009), la apertura del capítulo de la parrhesía está marcada por el propio Foucault, señalando cierta discontinuidad en sus investigaciones en aquel momento. Sin embargo, ese decir veraz crítico nos remite de manera inexorable a reflexiones que se habían producido con anterioridad en la obra del filósofo francés, y que pone en marcha una actualización de su propio pensamiento desde un ángulo renovado. 


\section{Bibliografía}

Adorno, F. P. (2010). La tarea del intelectual: el modelo socrático. En Foucault, el coraje de la verdad (pp. 33-54). Madrid: Arena Libros.

Alvarez Yagüez, J. (2013). El último Foucault. Voluntad de verdad y subjetividad. Madrid: Biblioteca Nueva.

Castro, R. (2005). Etica para un rostro de arena. Michel Foucault y el cuidado de la libertad. Universidad Complutense de Madrid. Recuperado a partir de http://eprints.ucm.es/ tesis/fsl/ucm-t28231.pdf

Cremonesi, L., Irrera, O., Lorenzini, D., \& Tazzioli, M. (2014). Introduzione. Materiali foucaultiani, 3(5-6), 9-13.

Cruz, M. (2002). La confianza en la ciencia. En Filosofía contemporánea (pp. 119-127). Taurus.

Deleuze, G. (2003). Foucault. Barcelona: Paidós.

Dreyfus, H. L., \& Rabinow, P. (2001). Michel Foucault, más allá del estructuralismo y la hermenéutica. Buenos Aires: Ediciones Nueva Visión.

Eagleton, T. (1997). Ideología. Una introducción. Barcelona: Paidós.

Eribon, D. (1995). Michel Foucault y sus contemporáneos. Buenos Aires: Ediciones Nueva Visión.

Eribon, D. (2004). Michel Foucault. Barcelona: Anagrama.

Folkers, A. (2016). Daring the Truth: Foucault, Parrhesia and the Genealogy of Critique. Theory, Culture \& Society, 33(1), 3-28. https://doi.org/10.1177/0263276414558885

Fortanet, J. (2010). Dos modos de concebir la labor intelectual: Foucault y Rorty. Isegoría, (42), 215-229. https://doi.org/10.3989/isegoria.2010.i42.692

Foucault, M. (1988). El sujeto y el poder. Revista mexicana de sociología, 50(3), 3-20.

Foucault, M. (1993a). About the Beginning of the Hermeneutics of the Self: Two Lectures at Dartmouth. Political Theory, 21(2), 198-227.

Foucault, M. (1993b). ¿Qué es la Ilustración? Daimon Revista Internacional de Filosofía, (7), 5-18.

Foucault, M. (1995). ¿Qué es la crítica? (Crítica y Aufklärung). Daimon Revista Internacional de Filosofía, (11), 5-26.

Foucault, M. (1999). La filosofía analítica de la política. En A. Gabilondo (Trad.), Estética, ética y hermenéutica. Obras esenciales (Vol. 3, pp. 111-128). Barcelona: Paidós.

Foucault, M. (2000a). La verdad y las formas jurídicas. En Fernando Alvarez Uría \& Julia Varela (Trads.), Estrategias de poder. Obras esenciales (Vol. 2, pp. 169-281). Barcelona: Paidós.

Foucault, M. (2000b). Verdad y poder. En Fernando Alvarez-Uría \& Julia Varela (Trads.), Estrategias de poder. Obras esenciales (Vol. 2, pp. 41-55). Barcelona: Paidós.

Foucault, M. (2003). Introducción. En Historia de la sexualidad II: el uso de los placeres $\left(1^{\circ}\right.$, pp. 7-35). Buenos Aires: Siglo XXI.

Foucault, M. (2004a). Discurso y Verdad en la Antigua Grecia. (Fernando Fuentes Megías, Trad.). Barcelona: Paidós.

Foucault, M. (2004b). La arqueología del saber. (Aurelio Garzón del Camino, Trad.). Buenos Aires: Siglo XXI. 
Foucault, M. (2005). La hermenéutica del sujeto. Curso del Collège de France (1981-1982). (F. Gros, Ed., H. Pons, Trad.). Madrid: Akal.

Foucault, M. (2006). Seminario sobre el texto de Kant «Was ist Aufklärung?» En Eduardo Bello (Trad.), Sobre la Ilustración (pp. 53-71). Madrid: Tecnos.

Foucault, M. (2009). El gobierno de sí y de los otros. Curso del Collège de France (19821983). (F. Gros, Ed., H. Pons, Trad.). Buenos Aires: Fondo Cultura Económica.

Foucault, M. (2010). El coraje de la verdad: el gobierno de sí y de los otros II. Curso en el Collège de France (1983-1984). (F. Gros, Ed., H. Pons, Trad.). Buenos Aires: Fondo de Cultura Económica.

Foucault, M. (2012). Du gouvernement des vivants : Cours au Collège de France (19791980). (M. Senellart, Ed.). Gallimard/Seuil.

Foucault, M. (2015).Parrēsia. Critical Inquiry, 41(2), 219-253.https://doi.org/10.1086/679075

Foucault, M., \& Deleuze, G. (2000). Los intelectuales y el poder. En Fernando Alvarez-Uría \& Julia Varela (Trads.), Estrategias de poder. Obras esenciales. (Vol. 2, pp. 105-115). Barcelona: Paidós.

Gabilondo, A., \& Fuentes Megías, F. (2004). Introducción. En Discurso y Verdad en la Antigua Grecia (pp. 11-33). Barcelona: Paidós.

Gros, F. (2009). Situación del curso. En El gobierno de sí y de los otros. Curso del Collège de France (1982-1983) (pp. 379-394). Buenos Aires: Fondo Cultura Económica.

Gros, F. (2010a). La parresía en Foucault (1982-1984). En Foucault, el coraje de la verdad (pp. 131-140). Madrid: Arena Libros.

Gros, F. (2010b). Situación del curso. En El coraje de la verdad: el gobierno de sí y de los otros II. Curso en el College de France (1983-1984) (pp. 351-366). Buenos Aires: Fondo de Cultura Economica.

Lanceros, P. (1997). El «proyecto general» de Michel Foucault. Revista de Filosofía, X(18), 159-186.

Lorenzini, D. (2010). Para acabar con la verdad-demostración. Bachelard, Canguilhem, Foucault y la historia de los «regímenes de verdad». Laguna: Revista de filosofía, (26), 9-34.

Mascaretti, G. M. (2014). Michel Foucault on Problematization, Parrhesia and Critique. Materiali Foucaultiani, 3(5-6), 135-154.

Moreno Pestaña, J. L. (2011). Foucault y la política. Madrid: Tierra de nadie.

Morey, M. (1999). Por una políticia de la experiencia. En Entre filosofía y literatura. Obras Esenciales. (pp. 9-24). Barcelona: Paidós.

Poster, M. (1987). Foucault, Marxismo e Historia. Argentina: Paidós.

Rambeau, F. (2012). La critique, un dire vrai. Cahiers philosophiques, 130 (Foucault, une politique de la vérité), 29-38. https://doi.org/10.3917/caph.130.0029

Revel, J. (2014). Foucault. Un pensamiento de lo discontinuo. Buenos Aires: Amorrortu.

Terrel, J. (2012). De la critique de la volonté de vérité au courage de la vérité. Cahiers philosophiques, 130 (Foucault, une politique de la vérité), 7-28. https://doi.org/10.3917/ caph.130.0007 